\title{
A PERSPECTIVA DISCENTE RELACIONADA AO USO DE DISPOSITIVOS ELETRÔNICOS NO AMBIENTE ACADÊMICO
}

\author{
SÃO PAULO/SP JUNHO/2018 \\ Carla Oliveira Dias - UNISA - carla4029@gmail.com \\ Tipo: Investigação Científica (IC) \\ Natureza: Descrição de Projeto em Andamento \\ Categoria: Métodos e Tecnologias \\ Setor Educacional: EDUCAÇÃO SUPERIOR
}

RESUMO

\begin{abstract}
Resumo
O ambiente educacional no mundo contemporâneo, a partir do advento das Tecnologias Digitais de Informação e Comunicação (TDICs), vem incorporando de forma significativa os dispositivos eletrônicos, móveis ou não, no processo ensino-aprendizagem. Este artigo tem como objetivo apresentar a percepção de graduandos, do ensino superior tecnológico, sobre a utilização de dispositivos eletrônicos no cotidiano acadêmico. Trata-se de um estudo de campo exploratóriodescritivo, que contou com a participação voluntária de 119 graduandos de uma universidade privada de São Paulo, Brasil. Os resultados evidenciaram que os graduandos utilizam em larga escala dispositivos eletrônicos em suas atividades acadêmicas, sendo o celular do tipo smartphone o principal aparato tecnológico encontrado no local de estudo. Os participantes elegem como principal beneficio dos dispositivos eletrônicos o acesso a informações em rede e a interconectividade global e apontam como desvantagens a possibilidade de dispersão do aluno para o mundo virtual durante as aulas e 0 excesso de informações disponíveis. Os resultados possibilitam concluir que os dispositivos eletrônicos são percebidos pelos discentes como ferramentas tecnológicas que podem auxiliá-los em suas atividades acadêmicas, necessitando porém de mediação pedagógica do docente para à obtenção de resultados satisfatórios.
\end{abstract}

Palavras-chave: Ensino Superior. Tecnologias Educacionais. Tecnologias Digitais da Informação e Comunicação. Aprendizagem. 


\section{INTRODUÇÃO}

A linguagem digital é resultado direto da evolução das tecnologias comunicacionais de massa, intituladas de modo geral como Tecnologias Digitais de Informação e Comunicação (TDICs), advento contemporâneo que surgiu com a evolução do ciberespaço e da Cibercultura (LEVY, 2010; LEMOS, 2013). Segundo Castells (2000, p. 25) as tecnologias comunicacionais geram um processo comunicacional interativo, dinâmico e globalizado, que implica diretamente na democratização das informações, para esse autor "a tecnologia passa a representar a sociedade, e a sociedade não pode ser entendida sem suas ferramentas tecnológicas", daí o fato de os dispositivos eletrônicos tornarem-se cada vez mais essenciais e populares em todos os ramos da sociedade. $\mathrm{Na}$ área da educação, a interconexão global e a competência informacional agregaram novos sentidos ao processo de ensinar e aprender, possibilitando em muitos momentos que o discente assuma o protagonismo de sua aprendizagem, pois, como em outros ramos da sociedade, "a tecnologia adentrou as universidades desalojando sentidos naturalizados por uma prática, de certa forma reprodutiva dos modos de ensinar/aprender, ocasionando mudanças" (TORRES; PIMENTA; KERBAUY, 2017, p. 141), quase irreversíveis que ressignificaram, de certo modo, os processos de ensino e aprendizagem.

Visto ser a linguagem digital uma realidade que se impõe socioculturalmente no país e no mundo e considerando que a maior parte dos discentes é composta por nativos digitais, a reflexão sobre o uso de dispositivos eletrônicos no contexto educacional brasileiro torna-se um tema relevante, porém, ainda é pouco estudado por especialistas na área da educação (ALMEIDA; ARAÚJO JR, 2013). Assim, neste artigo serão realizadas algumas reflexões sobre a presença dos dispositivos eletrônicos no ensino superior decorrentes de uma pesquisa que objetivou identificar a percepção de graduandos em relação à utilização de dispositivos eletrônicos no cotidiano acadêmico. O referencial teórico que fundamentou tais reflexões baseou-se nos estudos de Levy (2010), Lemos (2013), Castells (2000), Prensky (2001), além de pesquisas empíricas relacionadas ao tema.

\section{PROCEDIMENTOS METODOLÓGICOS}

O presente estudo refere-se a resultados parciais de uma pesquisa de mestrado, em curso intitulada "A Cultura Digital e a produção de conhecimento sob o olhar do discente". Trata-se de uma pesquisa de campo que busca identificar a percepção dos discentes em relação à tecnologia em seu cotidiano acadêmico. O estudo está sendo desenvolvido em uma instituição de ensino superior privado no município de São Paulo. 
Os participantes do estudo foram graduandos matriculados no último semestre. A amostra foi composta de 119 participantes, coletada no ano de 2018, em um universo de 130 graduandos matriculados. O questionário compôs-se de 4 questões no modelo de Escala de Likert. $O$ estudo seguiu todos os princípios éticos relacionados às pesquisas educacionais, obtendo, também, a devida aprovação do Comitê de Ética e Pesquisa da instituição de ensino à qual a pesquisadora é vinculada, com parecer favorável protocolado sob o ${ }^{\circ} 2.133 .085 / 2017$.

\section{APRESENTAÇÃO E DISCUSSÃO DOS RESULTADOS}

Neste recorte, os dados foram agrupados em tópicos, segundo a ordem de questionamentos apresentada aos participantes de modo que, inicialmente, organizouse uma breve caracterização do perfil dos graduandos, na sequência foram apresentados os dispositivos eletrônicos mais utilizados no local de estudo e, por fim, os resultados relacionados à questão norteadora deste artigo: como graduandos do ensino superior tecnológico percebem a utilização de recursos eletrônicos em seu cotidiano acadêmico.

\section{Caracterização dos sujeitos da pesquisa}

Os resultados possibilitaram a caracterização do perfil dos graduandos quanto ao gênero, idade, estado civil e inserção no mercado de trabalho. Conforme os resultados apresentados na tabela 1 é possível observar que a maioria dos acadêmicos é do gênero feminino, adultos jovens na faixa etária entre 18 e 30 anos, perfil que corresponde praticamente a $73 \%$ da amostra. 
Tabela 1 - Perfil dos graduandos de um curso superior tecnológico, em uma universidade privada, São Paulo, 2018.

\begin{tabular}{|c|c|c|}
\hline GÊNERO & $\mathbf{N}^{\circ}$ & $\%$ \\
\hline Masculino & 47 & 39,49 \\
\hline Feminino & 72 & 60,50 \\
\hline TOTAL & 119 & $100 \%$ \\
\hline FAIXA ETÁRIA & $\mathbf{N}^{\circ}$ & $\%$ \\
\hline $18-25$ anos & 62 & 52,10 \\
\hline $26-30$ anos & 25 & 21,00 \\
\hline 30 anos ou + & 29 & 24,36 \\
\hline Sem resposta & 03 & 02,52 \\
\hline TOTAL & 119 & $100 \%$ \\
\hline ESTADO CIVIL & $\mathbf{N}^{\circ}$ & $\%$ \\
\hline Solteiro & 87 & 73,10 \\
\hline Casado & 22 & 18,48 \\
\hline Outros & 07 & 05,88 \\
\hline Sem resposta & 03 & 02,52 \\
\hline TOTAL & 119 & $100 \%$ \\
\hline EXPERIÊNCIA PROFISSIONAL & $\mathbf{N}^{\circ}$ & $\%$ \\
\hline Está trabalhando & 88 & 73,94 \\
\hline Não está trabalhando & 30 & 25,20 \\
\hline Nunca trabalhou & 01 & 00,84 \\
\hline TOTAL & 119 & $100 \%$ \\
\hline
\end{tabular}

Fonte: O autor (2018).

Em relação ao estado civil, a maioria dos participantes encontra-se representada socialmente pelo estado civil solteiro. Já, no que se refere ao quesito experiência profissional, é possível identificar que a maioria dos participantes já se inseriu no mercado de trabalho ou, pelo menos, já participou do mundo do trabalho em algum momento.

\section{Dispositivos eletrônicos utilizados no local de estudo.}

Para a melhor compreensão sobre a utilização de dispositivos eletrônicos no contexto educacional estudado, a pesquisadora formulou questionamentos sobre o conhecimento e a utilização de dispositivos eletrônicos e digitais no cotidiano acadêmico e também sobre a sua possível correlação com o processo de aprendizagem discente. A pergunta norteadora que compôs este tópico foi: com que frequência você utiliza dispositivos eletrônicos para auxiliar seus estudos? As opções apresentadas, em ordem alfabética, foram: celular, desktop, tablet, notebook. A figura abaixo representa o rol de respostas obtidas em relação aos dispositivos eletrônicos mais utilizados no local de estudo. 
Figu ra 1 - Distribuição do percentual de utilização dos dispositivos eletrônicos como auxílio aos estudos, São Paulo, 2018.

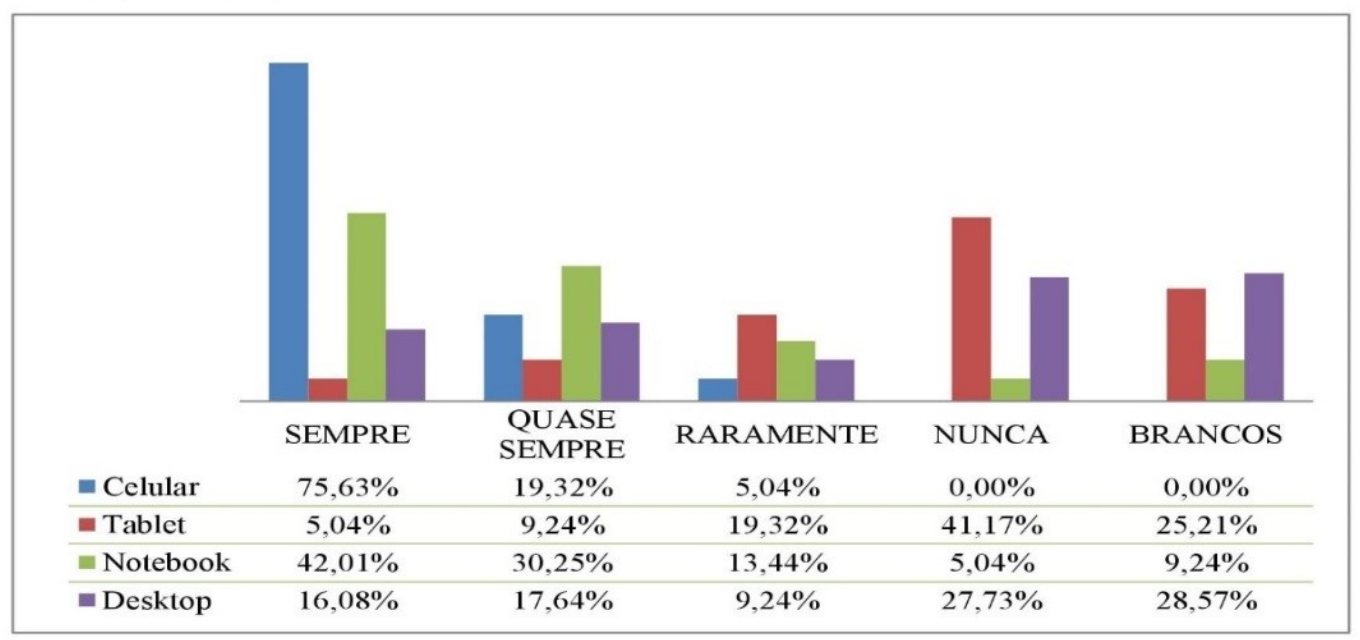

Fonte: O autor (2018)

Os resultados na figura acima evidenciam a preferência dos discentes pelo uso do celular, os questionamentos da pesquisa também evidenciaram que em relação a este aparato tecnológico o smartphone é o tipo de aparelho celular mais utilizado pelos participantes do estudo. Isso ocorre, porque os participantes valorizam principalmente sua capacidade interativa e multifuncional, comparando-o a uma central de serviços. No que tange à percepção sobre a utilização dos dispositivos móveis no cotidiano acadêmico, os resultados apresentam o notebook como segunda opção de apoio tecnológico para a realização de atividades acadêmicas. O desktop foi considerado um recurso secundário, relacionado à operacionalização de atividades educativas relacionadas à produção de textos, sendo pouco relacionado ao quesito acesso para navegação em rede, embora esse dispositivo também permita tal ação.

Um dado relevante que chama a atenção são os percentuais obtidos em relação ao uso do tablet, que apesar de representar um dispositivo móvel tecnologicamente avançado, foi relegado à segunda plano. Isso acontece porque o tablet, além, do tamanho desfavorável quando comparado ao smartphone, também não possui a diversidade de funções deste. Os resultados evidenciam que os graduandos utilizam o celular e o notebook como ferramentas tecnológicas para apoiar sua aprendizagem, porque o celular é uma ferramenta que pode facilmente ser incorporada as demandas do ambiente acadêmico.

Esses resultados corroboram com o estudo de Barbosa e colaboradores (2018), que investigando o impacto da utilização de novas tecnologias na rotina de acadêmicos de medicina em uma universidade na região nordeste do Brasil, observou que os dispositivos móveis são largamente utilizados para acessar aplicativos educacionais que apoiam atividades acadêmicas, bem como aplicativos que permitem a interação social. 
Barbosa e colaboradores (2018). Outra questão que emerge desta realidade é o fato de que para a sua utilização, não há qualquer dispêndio para as instituições de ensino, pois o investimento é particular, trata-se de um equipamento pessoal comum à maior parte das pessoas de modo que "se o computador ainda é um objeto restrito, o celular está presente em boa parte das escolas, nas mochilas dos alunos de diferentes classes sociais" (MERIJE, 2012, p.81).

O conhecimento desses resultados leva-nos à compreensão de que a cultura digital já se encontra impregnada no modo de vida dos jovens pesquisados, sendo o telefone celular a ferramenta tecnológica que melhor permite que eles se expressem no contexto da cultura digital, permitindo que os discentes utilizem a linguagem digital em seu cotidiano. A conectividade, oportunizada por esses dispositivos móveis inclusive a maior presença nas redes sociais, é um fator que confere sentimento de inclusão e importância no cenário de interação global (CASTELLS, 2000). Diante dos resultados presentes neste tópico de discussão, é possível inferir que os dispositivos eletrônicos apresentam potencial pedagógico para apoiar o discente na construção de sua autonomia para a aprendizagem, além de impactar positivamente na comunicação em rede, fator favorável à construção da identidade social do discebte.

\section{Utilização de dispositivos eletrônicos no ambiente acadêmico - vantagens e desvantagens.}

No contexto da pesquisa, também foi investigado junto aos participantes a percepção deles sobre as possíveis vantagens e desvantagens quanto à utilização dessa ferramenta tecnológica para o seu aprendizado acadêmico. Para responder a essa indagação, foi elaborado um questionamento na forma de uma escala modulada crescente do tipo 'grau de importância', permitindo que cada participante pudesse atribuir a cada quesito um valor em ordem crescente, em escala numérica de 1 a 5 . Os resultados que representam a percepção discente, nesta perspectiva, são apresentados no quadro 1 e quadro 2. 
Quadro 1 - Vantagens atribuídas por graduandos ao uso de dispositivos eletrônicos em uma universidade privada na cidade de São Paulo, 2018.

\begin{tabular}{|l|c|c|}
\hline \multicolumn{1}{|c|}{ Uso de dispositivos eletrônicos - vantagens } & $\begin{array}{c}\text { Ordem de } \\
\text { importância }\end{array}$ & $\begin{array}{c}\text { Respostas } \\
\text { atribuídas }\end{array}$ \\
\hline Acesso a diferentes materiais de apoio. & $1^{\circ}$ & 46 \\
\hline $\begin{array}{l}\text { Proporcionar a realização de atividades colaborativas extra sala de } \\
\text { aula. }\end{array}$ & $2^{\circ}$ & 24 \\
\hline Conferir e validar informações sobre conteúdos ministrados. & $3^{\circ}$ & 21 \\
\hline $\begin{array}{l}\text { Organização de materiais e anotações referentes a conteúdos } \\
\text { estudados }\end{array}$ & $4^{\circ}$ & 19 \\
\hline $\begin{array}{l}\text { Participação em fóruns e espaços de discussão relacionados aos } \\
\text { conteúdos estudados. }\end{array}$ & $5^{\circ}$ & 17 \\
\hline
\end{tabular}

Fonte: $\mathrm{O}$ autor (2018)

Observa-se no quadro 1 a valoração atribuída aos dispositivos eletrônicos em relação ao seu potencial para melhorar o processo de aprendizagem. Os resultados presentes neste quadro podem ser compreendidos se considerados a partir de duas perspectivas distintas, sendo a primeira composta pelo $1^{\circ}, 2^{\circ}$, $3^{\circ}$ e $5^{\circ}$ lugares, com tópicos que apresentam em sua ideia central a capacidade interação e comunicação em rede mediada pela Internet. Já a segunda perspectiva, que comporta apenas o $4^{\circ}$ lugar, refere-se à questão da capacidade operacional de tais dispositivos para produzir trabalhos acadêmicos, que de modo geral, permitem organizar conteúdos disciplinares. $\mathrm{Na}$ primeira perspectiva estão presentes $01^{\circ}, 2^{\circ}, 3^{\circ}$ e $5^{\circ}$ lugares. Os graduandos atribuíram o $1^{\circ}$ lugar, como principal benefício, ao tópico que trata do livre acesso a diferentes materiais acadêmicos, inferência que na pratica acadêmica representa a possibilidade de conhecer e manipular conteúdos de apoio disciplinar, de forma diversificada e ampliada, na rede virtual.

O acesso livre à rede e a troca de informações continuam a serem as principais ideias no $2^{\circ}$ e $3^{\circ}$ lugares, isso pode ser evidenciado quando os participantes reconhecem como benefícios principais a realização de atividades colaborativas e a possibilidade de revisão das informações transmitidas pelo professor fora da sala de aula. O 5 o lugar é aquele que mais explicita o reconhecimento do valor atribuído às atividades colaborativas, em tempo real ou não, isso fica claro quando os participantes atribuem grau de importância à participação em fóruns de discussões atividade extra sala de aula. Os resultados presentes, nesta perspectiva, evidenciam a quão valorizada é a capacidade de interconexão global, já que todos os benefícios de uma forma ou de outra acontecem mediante a troca de informações por conectividade. Em contrapartida, a segunda perspectiva avaliada no quadro 1 , representada pelo $4^{\circ}$ lugar em grau de importância, refere-se ao beneficio relacionado à capacidade que tais dispositivos têm para auxiliar na organização do trabalho discente, pois permitem a elaboração e a organização textual dos conteúdos disciplinares. 
$\mathrm{Na}$ sequência, o quadro 2 apresenta questões que se contrapõem às apresentadas no quadro 1, ou seja, tratam-se dos aspectos negativos relacionados ao uso de dispositivos eletrônicos no cotidiano acadêmico, aqui compreendido pelos participantes do estudo como desvantagens para a aprendizagem.

\footnotetext{
Quadro 2 - Desvantagens atribuídas por graduandos ao uso de dispositivos eletrônicos em uma universidade privada na cidade de São Paulo, 2018.
}

\begin{tabular}{|l|c|c|}
\hline \multicolumn{1}{|c|}{ Uso de dispositivos eletrônicos - desvantagens } & $\begin{array}{c}\text { Ordem de } \\
\text { importância }\end{array}$ & $\begin{array}{c}\text { Respostas } \\
\text { atribuídas }\end{array}$ \\
\hline $\begin{array}{l}\text { Em alguns momentos a aprendizagem pode ser prejudicada porque o } \\
\text { acesso fácil ao mundo virtual possibilita a perda de foco, pois novas } \\
\text { possibilidades de endereços eletrônicos (sites) são ofertados aos alunos } \\
\text { em seus resultados de busca, causando assim, desinteresse pelo tema } \\
\text { inicial no momento do acesso. }\end{array}$ & $1^{\circ}$ & 32 \\
\hline $\begin{array}{l}\text { Ao acessar a internet, o volume excessivo de informações obtidas pode } \\
\text { dificultar a escolha dos materiais que de fato, estão relacionados aos } \\
\text { temas estudados. }\end{array}$ & $2^{\circ}$ & 23 \\
\hline $\begin{array}{l}\text { Proporciona respostas e soluções imediatas, diminuindo a possibilidade } \\
\text { de questionamentos e discussões mais aprofundadas. }\end{array}$ & $3^{\circ}$ & 21 \\
\hline $\begin{array}{l}\text { Oferece imagens e textos já estruturados reduzindo o estímulo para a } \\
\text { produção de novos de conteúdos. }\end{array}$ & $4^{\circ}$ & 19 \\
\hline $\begin{array}{l}\text { O acesso às tecnologias na sala da aula causa interferência desfavorável } \\
\text { no processo de comunicação. }\end{array}$ & $5^{\circ}$ & 15 \\
\hline
\end{tabular}

Fonte: O autor (2018)

Os resultados anteriores (quadro 2) permitem inferir que a maior parte da amostra considera como principal desvantagem dos dispositivos eletrônicos para a aprendizagem ( $1^{\circ}$ lugar) a possível perda de foco do discente relacionada à atividade executada em sala de aula ou mesmo em casa; fenômeno conhecido como abstração virtual em momento inoportuno. O $2^{\circ}$ e o $3^{\circ}$ lugares cômodos aspectos desvantajosos foram, respectivamente, atribuídos aos itens relacionados à questão do excesso de informações disponíveis na rede e à possibilidade de repostas imediatas, na maioria das vezes, de caráter superficial e duvidoso. Os participantes acreditam que esses elementos podem, de modo geral, dificultar a escolha de temas a serem estudados $e$ também prejudicar a qualidade técnica e teórica da das discussões durante as atividades acadêmicas.

Ainda no escalonamento das possíveis desvantagens, os participantes atribuem o $4^{\circ}$ lugar à padronização de modelos já estruturados disponíveis em excesso na rede. Os sujeitos inferem que esse fator pode vir a engessar a criatividade e ainda diminuir 0 desenvolvimento de habilidades relacionadas à elaboração de conhecimento original. $O$ último item visto como desvantagem, em $5^{\circ}$ lugar, foi o isolamento comunicacional intra sala de aula. Os participantes referem que, algumas vezes, os dispositivos eletrônicos podem colaborar para que os discentes permaneçam imersos no mundo virtual, deixando assim de comunicarem-se, adequadamente, com seus pares no ambiente 
acadêmico.

Assim é possível inferir, à luz dos resultados, que existe relação direta de causalidade entre os fenômenos descritos no $1^{\circ}, 2^{\circ}$ e $3^{\circ}$ lugares com os fenômenos descritos no $4^{\circ}$ e 5 ํ lugares já que a dispersão no mundo virtual, o volume excessivo de informações e a baixa qualidade das informações disponíveis, que compõem o rol de desvantagens apresentadas nos $1^{\circ}, 2^{\circ}$ e $3^{\circ}$ lugares, podem vir a influenciar diretamente a comunicação interpessoal e a qualidade do conhecimento produzido ( $4^{\circ}$ e $\left.5^{\circ}\right)$ durante as atividades acadêmicas. Desse modo, a possível observar melhoria dos três primeiros itens negativos poderia vir a diminuir ou sanar as desvantagens apresentadas no final da escala.

Em estudos em que se avaliam os possíveis efeitos do uso de dispositivos móveis na aprendizagem e a interação social de adolescentes, Kobs (2017) evidenciou também problemas relativos à abstração virtual, ao volume excessivo de informações disponíveis na rede e à superficialidade dos conteúdos presentes no rol de informações compartilhadas na Internet. Este autor, considera tais fatores prejudiciais à aprendizagem significativa, argumentando que para que o uso de dispositivos eletrônicos no contexto educativo aconteça de forma favorável, é preciso que ocorra a devida mediação pedagógica do docente.

\section{CONSIDERAÇÕES FINAIS}

Os resultados permitiram observar que os graduandos, em sua maior parte, percebem de forma positiva a inserção de dispositivos eletrônicos no ambiente acadêmico e que também já os utilizam em muitas atividades educacionais, principalmente, os aparelhos celulares e notebooks. As principais atividades educacionais mediadas por dispositivos eletrônicos referem-se à captação de informações e conteúdos disciplinares disponíveis na rede virtual e atividades operacionais de produção e organização de trabalhos acadêmicos (produção de textos, leitura etc.). Os resultados evidenciam, ainda, a importância que os graduandos atribuem ao aparelho celular, na modalidade smartphone, elevando-o à categoria de ferramenta tecnológica indispensável ao processo de construção de conhecimentos acadêmicos no ensino superior.

A pesquisa também demonstrou a maturidade dos participantes para identificarem as vantagens e desvantagens em relação à presença dos dispositivos eletrônicos no ambiente acadêmico, relacionando o acesso à rede comunicacional e a interatividade como as principais vantagens da utilização de tais ferramentas, mas em contrapartida identificando o seu potencial para propiciar a perda de foco pela imersão no mundo 
virtual e a consequente diminuição da capacidade de interação com os professores e colegas, elementos que podem interferir na capacidade criativa e nas habilidades de produção de conhecimento original. Sugerem-se, assim, novos estudos sobre a utilização dos dispositivos eletrônicos no ensino superior, principalmente sobre os dispositivos móveis, pois estes já dominam, informalmente, os ambientes de ensino e não se pode mais negar o fenômeno da cultura digital neste contexto

\section{REFERÊNCIAS}

ALMEIDA, Rosiney Rocha; ARAÚJO JR, Carlos Araújo Fernando de. O Uso de Dispositivos Móveis no Contexto Educativo. Revista Tempo e Espaços em Educação; v. 6, n. 11; jul./dez.2013.

BARBOSA, Sylvio Elvis da Silva Barbosa et al. Impacto na Rotina Acadêmica pela Utilização de Novas Tecnologias. Id on Line Rev. Mult. Psic. V.12, N. 39., 2018.

CASTELLS, Manuel. A Sociedade em Rede. Ed. São Paulo. Editora Paz e Terra, 2000.

KOBS, Fabio Fernando. Os possíveis efeitos do uso dos dispositivos móveis por adolescentes: análise de atores de uma escola pública e uma privada. 2017. $243 \mathrm{f}$. Tese (Doutorado em Tecnologia e Sociedade), Universidade tecnológica Federal do Paraná. Curitiba.

LEMOS, André. A comunicação das coisas: Teoria Ator-Rede e cibercultura. São Paulo: Annablume, 2013.

LÉVY Pierre. Cibercultura. 3. ed. Tradução de Carlos Irineu da Costa. São Paulo: Ed.34, 2010.

MERIJE, Wagner. Movimento: educação e comunicação mobile. São Paulo: Petrópolis, 2012.

PRENSKY, Marc. Digital natives, digital immigrants. On de Horizon, vol. 9, n.05, 2001.

TORRES, Ana Paula; PIMENTA, Leny André; KERBAUY, Maria Teresa Miceli. O uso efetivo das tecnologias de informação e comunicação no ensino superior. Conhecimento \& Diversidade, v.9, n. 18, p. 123-143, jan.2018. 